\title{
DESAFIOS DA PRÁTICA DOCENTE UNIVERSITÁRIA NA EDUCAÇÃO A DISTÂNCIA
}

\author{
Cláudia Starling Bosco ${ }^{1}$ \\ Marilza de Oliveira Santos ${ }^{2}$ \\ Edmilson Minoru Torisu ${ }^{3}$
}

\begin{abstract}
Resumo: O artigo busca compreender a prática pedagógica de professores recém-doutores durante suas primeiras experiências na educação a distância, tendo como foco principal a formação docente no contexto universitário. Buscamos refletir sobre os desafios enfrentados pelos sujeitos investigados analisando suas narrativas escritas após as primeiras experiências na docência na $\mathrm{EaD}$. Os estudos sobre narrativas (auto)biográficas balizam metodologicamente a coleta e análise de dados. Ao revisitarem suas trajetórias de inserção na $\mathrm{EaD}$, os sujeitos têm a oportunidade de construírem e reconstruírem seus saberes sobre a docência no contexto universitário. Sabemos que as tecnologias têm favorecido novas concepções sobre o que é ensinar, foco da Didática. Os resultados apontam a necessidade e a urgência de formação docente no que se refere à educação a distância universitária.
\end{abstract}

Palavras-chave: EaD; Prática pedagógica; Formação docente no Ensino Superior.

\section{CHALLENGES OF UNIVERSITY TEACHING PRACTICE IN DISTANCE EDUCATION}

\begin{abstract}
The present paper aims to understand the pedagogical practice of newly doctoral graduated teachers during their first experiences in distance learning, focusing mainly on teacher training in the university context. We seek to pounder on the challenges faced by the investigated subjects analyzing their written narratives after the first experiences teaching in distance education. Studies on (auto)biography narratives methodologically guide the collection and analysis of data. When revisiting their paths of insertion in distance education, the subjects have the opportunity to build and reconstruct their knowledge about teaching in the university context. We do know that technologies have favored new conceptions of what it is to teach, which is what Didactics is focused on. The results point out the necessity and urgency for teacher training regarding university distance education.
\end{abstract}

Keywords: Distance Education. Pedagogical practice. Teacher training in Higher Education.

\footnotetext{
${ }^{1}$ Doutora em Educação, Professora Adjunta de Didática e no Programa de Mestrado Profissional (Promestre) na linha Didática e docência - Universidade Federal de Minas Gerais

${ }^{2}$ Doutora em Educação, Professora de Didática da Universidade do Estado de Minas Gerais (UEMG).

${ }^{3}$ Doutor em Educação pela UFMG, Professor Adjunto do Departamento de Educação Matemática e do Mestrado em Educação Matemática - Universidade Federal de Ouro Preto (UFOP).
} 


\section{INTRODUÇÃO}

Embora o uso das tecnologias na educação tenha favorecido novas concepções sobre o que é ensinar, tal qual é o foco da Didática, a formação de professores para a docência, em um contexto de educação a distância, tem se tornado um dos grandes desafios no Ensino Superior, seja para os professores universitários ou para os estudantes de licenciatura, os quais futuramente também irão atuar nesta modalidade.

As pesquisas que abrangem o tema da docência no ensino superior apontam que o professor vivencia processos de socialização profissional e de construção de sua identidade, sendo evidenciados diversos percursos formativos. Para o desenvolvimento deste artigo, de caráter qualitativo, realizamos uma breve revisão da literatura sobre a $\mathrm{EaD}$ e docência universitária, com ênfase na formação docente. Fundamentamos em autores como Tardif (2000), Nóvoa (1995), Belloni (1999, 2005), Moran (2003, 2009), Behrens (2010), Melillo (2011), Lapa e Pretto (2010), Mill (2012) e Silva et al (2012).

Os estudos de Tardif (2000, p.13) apontam a necessidade de considerar a pesquisa a partir dos saberes dos professores, distanciando de uma perspectiva normativa, pois "os pesquisadores se interessam muito mais pelo que os professores deveriam ser, fazer e saber do que pelo que eles são, fazem e sabem realmente". Tardif (2000) aponta a existência de diferentes saberes e que muitas vezes "os alunos passam pelos cursos de formação de professores sem modificar suas crenças anteriores sobre o ensino. E, quando começam a trabalhar como professores, são principalmente essas crenças que eles reativam para solucionar seus problemas profissionais” (p.13).

De acordo com Nóvoa (1995) “a identidade não é um dado adquirido, porque em última análise tudo se decide no processo de reflexão que o professor leva a cabo sobre a sua própria ação" (p.16). Segundo o autor, a identidade está baseada em alguns princípios, como adesão, ação e autoconsciência, envolvendo os valores que baseiam a prática pedagógica, a tomada de decisão que o docente tem - que o coloca em constante ação - e a reflexão que possibilita sua ação. Neste contexto, o autor reforça a autonomia e desmistifica o mito da neutralidade na ação pedagógica, pois a "maneira como cada um de nós ensina está diretamente dependente daquilo que somos como pessoa quando exercermos o ensino" (NÓVOA, 1995, p.16).

Almeida (2011) sinaliza a importância de compreender a formação do professor universitário mediante o seu desenvolvimento profissional, refletindo sobre sua ação 
pedagógica e criação de espaços colaborativos de formação, a fim de que ele considere a docência como um compromisso político (p.19).

Metodologicamente, o estudo está baseado na vertente da narrativa (auto)biográfica, compreendendo que, ao revisitarem suas trajetórias de inserção na $\mathrm{EaD}$, os sujeitos têm a oportunidade de construírem e reconstruírem seus saberes sobre a docência no contexto universitário.

Buscamos, então, compreender a prática pedagógica de professores recémdoutores, egressos de um programa de pós-graduação em educação, durante suas primeiras experiências na educação a distância, discutindo as análises de suas narrativas (auto)biográficas. As seis narrativas analisadas foram escritas por professores, aqui denominados de Eduarda (Pedagogia), Carolina (Química), Rodrigo (Matemática), Luan (Matemática), Celso (História) e Luís (Física), que atuam em diferentes cursos de licenciatura em diversas universidades públicas estaduais ou federais. Estes seis professores, selecionados do grupo de egressos que atendiam ao grupo investigado (recém-doutor e professor universitário em cursos de licenciatura), foram convidados a participarem da pesquisa e solicitados a escreverem suas narrativas (auto)biográficas sobre a docência universitária. Os resultados apontados demonstram a necessidade e a urgência de políticas públicas de formação docente universitária no que se refere à educação a distância.

Lapa e Pretto (2010) sinalizam a existência de vários desafios e tensões em relação à prática docente na educação a distância. É justamente neste contexto teóricometodológico que este artigo se insere, apresentando o ponto de vista dos professores investigados sobre suas trajetórias e experiências na educação a distância, e desta forma, possibilitar a discussão de elementos fundamentais para a discussão das questões que envolvem a formação docente universitária.

\section{DOCÊNCIA UNIVERSITÁRIA E EDUCAÇÃO A DISTÂNCIA}

Discutir sobre a docência universitária envolve, dentre outros aspectos fundamentais, refletir sobre o papel do professor e por consequência, sua formação. Neste sentido, a questão torna-se ainda mais urgente quando abordamos mais especificamente a prática e a formação docente na educação a distância. Belloni (2005) aponta que a EaD tem crescido mundialmente, atendendo ao mercado e numa vertente capitalista de lucro e exploração do trabalho humano, mas que ao mesmo tempo traz 
novos paradigmas para o acesso à educação. Torna-se então necessário compreender seu contexto de expansão e, ao mesmo tempo, analisar as possibilidades que a educação a distância oferece diante do avanço das tecnologias. De acordo com a autora, "deve-se compreender a $\mathrm{EaD}$ como um tipo distinto de oferta educacional, que exige inovações ao mesmo tempo pedagógicas, didáticas e organizacionais (BELLONI, 2005, p. 190). A autora ainda sinaliza que em relação à formação docente, para atuar na educação a distância deve-se envolver três dimensões: a pedagógica, a tecnológica e a didática. Entretanto, os estudos de Behrens (2010) apontam que os recursos tecnológicos" são ferramentas, mas não a solução para a inovação da prática pedagógica do professor, pois ela depende da mudança de visão paradigmática”, uma vez que o professor está sendo desafiado atualmente a "enfrentar um processo de mudança necessário em sua prática docente" (p. 59).

De acordo com Moran (2009) e Vianney (2008), há vários modelos de EaD no Brasil. Desses, um que tem sido muito utilizado é o modelo web, muitas vezes constituído de duas partes: a virtual, na qual o contato entre professor e aluno é feito pela internet, e a semipresencial, na qual o estudante conta com o apoio de um polo presencial. Esse "modelo é replicado pelas universidades públicas, sob a gestão da UAB - Universidade Aberta do Brasil, que fazem parceria com as prefeituras para a instalação dos polos de apoio presenciais" (MORAN, 2009, p. 27).

A UAB, criada em 2006, não é exatamente uma universidade, pois não apresenta a estrutura convencional, com reitor, pró-reitores, institutos, etc. Ela é um sistema formado por instituições de ensino superior com apoio dos governos federal, estadual e municipal, que oferecem cursos de graduação e pós-graduação à distância.

O professor, ao atuar na EaD, seja por inserção voluntária ou por exigência da instituição em que trabalha, entrará, sem dúvidas, em um mundo novo. Sendo assim, poderá experimentar um misto de sensações, que incluem encantamento, estranheza e insegurança. Ao entrar em contato com esse novo ambiente, o professor, muitas vezes, sente-se inseguro, não sabendo como agir. Contudo, essa sensação vai sendo gradativamente abrandada à medida que mobiliza novos saberes docentes na busca por possibilidades para caminhar. Esses saberes geralmente se orientam na experiência, criados e recriados a partir de reflexões sobre a própria prática.

Entretanto, no caso do professor que vai começar a trabalhar na $\mathrm{EaD}$, o apoiar-se em experiências anteriores pode se tornar um grave problema, uma vez que seus parâmetros, muito provavelmente, foram construídos a partir de suas experiências na 
educação presencial na qual se formou e na qual passa a atuar, pois segundo Melillo (2011), a educação presencial assombra a EaD. Por outro lado, não podemos insistir na dualidade da formação para a educação a distância e para a presencial, já que os recursos tecnológicos estão disponíveis socialmente, em ambos os contextos de ensino.

Dessa forma, a dificuldade que se põe ao professor iniciante na $\mathrm{EaD}$ é conseguir agregar aos seus saberes docentes alguns outros conhecimentos, criando uma formulação (não prescritiva) que possa atender às suas demandas. Em outras palavras, é necessário que o professor ressignifique seu papel e aprenda a ser professor da EaD diante de novas concepções do que é ensinar e aprender.

As pesquisas na área sinalizam a existência de inúmeros desafios enfrentados pelo professor ao assumir esse novo papel. Por exemplo, os estudos de Lapa e Pretto (2010), que indicam alguns desses desafios docentes, como a preparação do curso, a desmistificação da separação entre professor e aluno, a necessidade do trabalho em equipe, a quantidade de alunos.

Em relação à preparação do curso, os autores sinalizam a necessidade de romper a estrutura de tempo e espaço cristalizada nos moldes da educação presencial. Enquanto no presencial a barreira da distância física não existe, na $\mathrm{EaD}$ o professor precisa encontrar saídas para mitigar a questão da interação. Soma-se a isso o problema dos materiais didáticos, muitas vezes organizados e preparados pelo denominado professor conteudista, que nem sempre está em contato com o professor ministrante ou compartilha com ele as mesmas concepções teóricas e ideológicas. Os autores alertam para o fato de que, no caso da $\mathrm{EaD}$, o material didático assume um papel muito mais importante na relação entre professor e aluno, porque é um dos principais artefatos que medeiam a comunicação entre eles. Ao recorrer ao material didático para sanar dúvidas que, presencialmente, poderia sanar com o professor, o estudante confere a esses materiais um papel de destaque em sua aprendizagem.

Ainda associado à forma de interação, outro desafio a ser vencido pelos professores na EaD é o de tornar-se mais próximo de seus alunos, interagindo de maneira efetiva a partir da mediação de recursos tecnológicos. Se na educação presencial a comunicação é síncrona, ocorre em tempo real, na EaD nem sempre isso é possível. Se na educação presencial a linguagem oral, corporal e o "olho-no-olho" são recursos per se, na EaD isso não é uma realidade, sempre. O professor muitas vezes prepara sua aula em estúdio falando, literalmente, "para as paredes". É comum que os professores nunca vejam seus alunos, de fato. 
Um terceiro desafio para o professor da EaD é aprender a trabalhar com uma equipe multidisciplinar, sobretudo de técnicos, que serão de importância crucial em todo o processo. Para uma aula presencial expositiva, por exemplo, o professor a prepara e é o porta voz daquele conteúdo, sendo o contato direto entre professor e aluno. $\mathrm{Na} \mathrm{EaD,} \mathrm{para} \mathrm{que} \mathrm{suas} \mathrm{ideias} \mathrm{cheguem} \mathrm{ao} \mathrm{conhecimento} \mathrm{dos} \mathrm{estudantes,} \mathrm{o}$ professor precisa do amparo de profissionais da área técnica que prepararão e ajustarão todos os recursos necessários a isso. O professor utilizará também novos conhecimentos no uso de recursos tecnológicos, mas há demandas que são de responsabilidade de outros profissionais. Por exemplo, um professor pode gravar uma videoaula e postá-la para seus alunos em uma plataforma digital. Contudo, ele não é o responsável pela criação propriamente dita da plataforma, o ambiente virtual onde sua aula será inserida. Sendo assim, cria-se uma nova forma de conceber a aula, não mais em um contexto individual, mas coletivo.

O professor que trabalha em parceria com uma equipe de profissionais da informática, web designers, tutores, etc. tem sido denominado professor coletivo (BELLONI, 1999), e sua atividade, de polidocência (MILL, 2012). Em outro estudo, Belloni (2005) aponta que é preciso considerar que a integração das tecnologias de informação e comunicação (TIC) no processo educativo requer compreender as mídias como objetos de estudos e também como recursos pedagógicos, além de apontar a necessidade de uma abordagem interdisciplinar.

Essa maneira de compreender as relações estabelecidas na EaD demonstra que essa modalidade de educação, para além do senso comum, requer a construção e reconstrução de novos saberes docentes, pois é preciso compreender o novo contexto em que o processo de ensino se efetiva, diferentemente do contexto presencial. Este novo profissional precisa se apropriar, no sentido Vygotskiano do termo, tornar seus, tornar próprios novos conhecimentos que irão favorecer uma atuação efetiva na $\mathrm{EaD}$.

Podemos acrescentar ao rol de desafios que se apresentam ao professor da $\mathrm{EaD}$ a necessidade de trabalhar com muitas turmas, muitos alunos em muitos polos. É claro que o apoio dos tutores, que compartilham com o professor os trabalhos com os alunos, é fundamental. Mesmo assim, orquestrar tudo isso exige novos saberes docentes, novas percepções sobre quem são os estudantes e como interagir no ambiente virtual.

Nesta mesma direção, Sá e Silva (2013), ao discutirem sobre a interatividade, apontam que os recursos tecnológicos incorporados pela esfera mercadológica imprimem transformações na esfera social, "não mais a prevalência da condição de 
receptor que recebe o produto pronto, mas a autonomia que contempla criar seu o conteúdo e o percurso da comunicação" (p.143). Os autores (2013, p.153) concebem o ambiente virtual como dinâmico, pois é sustentado a partir da mediação docente online e elementos que o integram.

Outros estudos na área, como os de Silva et al (2012) caracterizam e diferenciam a educação a distância $(\mathrm{EaD})$ da educação online (EOL) em relação ao desenho didático dos conteúdos e das atividades e à mediação. Em relação ao desenho didático, a EaD se caracteriza como um modelo predefinido, fechado e linear. Já a EOL, é considerada como um contexto colaborativo, mediado por tecnologias digitais e interativas. Em relação à mediação, os autores sinalizam que enquanto a EaD é instrucionista e baseada na transmissão, a partir de um contexto solitário e relações autoritárias de poder, na EOL é interacionista e colaborativa, sendo caracterizada por relações horizontais, sendo o docente um sujeito também em formação. Esses estudos apontam que muitas pesquisas utilizam os termos como sinônimos, mas que é importante demarcar as diferenças, principalmente porque usar $\mathrm{EaD}$ reforça o mito da distância, permitindo apenas a unidirecionalidade e trabalho solitário dos sujeitos. Ao contrário, a educação online traz a possibilidade "estar-junto on-line", numa perspectiva colaborativa e dialógica nas diversas possibilidades interativas, como fórum, chat, wiki, blog e redes sociais (p. 101).

Neste artigo, utilizamos o termo EaD não em uma perspectiva dicotômica e tradicional, mas redirecionando o conceito de distância para que não seja como fragmentada e unidirecional, e sim como um elemento importante, caracterizando que a educação se dá entre atores sociais que não estão necessariamente presentes fisicamente, mas mediados pelo uso de recursos tecnológicos. Compreende-se, dessa forma, que esta posição dos sujeitos não impõe uma fragmentação na relação, mas uma nova maneira de considerar as formas e meios em que a interação se realiza.

Em relação aos saberes docentes, Tardif (2000, p.13) afirma que estes são variados e heterogêneos, oriundos de diversas fontes, pois se baseiam na história de vida do docente, sua cultura e conhecimentos construídos na universidade, além de conhecimentos pedagógicos da sua formação profissional. Há também os saberes profissionais, que se constituem na ação, nos conhecimentos que mobilizam na prática pedagógica. Segundo o autor (2000, p.15), “um professor tem uma história de vida, é um ator social, tem emoções, um corpo, poderes, uma personalidade, uma cultura, ou mesmo culturas, e seus pensamentos e ações carregam as marcas dos contextos nos 
quais se inserem". Tardif (2000) sinaliza a importância de os professores que atuam no Ensino Superior pesquisarem e refletirem sobre suas práticas pedagógicas, a fim de não alargar ainda mais o abismo existente entre nossas "teorias professadas" e "praticadas" (p.21).

Torres e Almeida (2013) apontam que a docência universitária tem sido alvo de muitas transformações devido à multiplicidade de instituições e pela "dinamicidade da história e de políticas omissas e mercadológicas de formação de professores, entre outros aspectos que modificam continuamente a maneira de ensinar" (p.14). Atualmente, podemos incluir como um desses elementos a expansão do ensino superior na modalidade a distância. Para as autoras, há muitas tensões neste nível de ensino, como "a valorização dos conhecimentos específicos das diversas áreas em detrimento dos conhecimentos pedagógicos, o prestígio da pesquisa em detrimento do ensino de graduação, e as políticas públicas e institucionais omissas com tendência de mercado para a formação de professores" (p.15). As autoras inferem que "a educação superior não se preparou para essas mudanças e menos ainda os seus corpos docente e administrativo" (p.16).

Brzezinski (2002) argumenta que a construção da identidade docente se dá por meio de um processo dialético, no âmbito individual e no coletivo, sendo uma identidade coletiva. A autora considera a profissionalidade relacionada aos saberes e capacidades em um processo contínuo no qual se reconstroem e ressignificam de acordo com o contexto histórico e social (p.810).

Na mesma direção, Almeida (2011, p.12) aponta a necessidade da formação profissional específica para a docência, reconfigurando os modos de "ser professor", de "saber ser professor" e de "poder ser professor", em um processo contínuo de construção da identidade e desenvolvimento profissional, pois "isso requer que a formação seja vista contextualizadamente nos seus aspectos social, histórico, institucional e pedagógico, já que não pode ser separada das condições efetivas do exercício profissional da docência".

\section{ASPECTOS TEÓRICO-METODOLÓGICOS}

A escolha da narrativa (auto)biográfica como metodologia que embasa nosso estudo está relacionada às concepções sobre o lugar do sujeito na pesquisa no campo educacional. Ao adotarmos esta perspectiva teórico-metodológica, nos apoiamos nos 
estudos de autores como Souza (2013), Passeggi e Cunha (2013) e Delory-Momberger (2006).

Segundo Souza (2013), tal enfoque metodológico tem ganhado força no meio acadêmico se constituindo como uma rede internacional de pesquisas em educação. Diante do contexto atual que vivemos, de perdas de direitos que afetam significativamente a formação docente, o autor sinaliza que:

[...] vivemos momentos de crise, de legitimação e de interesses políticos sobre a formação de professores no Brasil, os quais perpassam desde o espaço de formação, à compreensão do que é formar, constituir-se professora, até às implicações e deformações legais e políticas preceituadas sobre formação de professores (SOUZA, 2006, p. 23).

A formação de professores torna-se então alvo de disputas e tensões exigindo que nós, professores pesquisadores, possamos refletir sobre as políticas públicas de formação docente que, muitas vezes, refletem mecanismos de controle e de desvalorização da formação e da profissão em função dos interesses econômicos (SOUZA, 2006). Nesta mesma direção, autores como Delory-Momberger (2006), afirmam que no processo de narrar suas experiências, o sujeito narra a história, e ao narrá-la, a ressignifica.

A seleção dos sujeitos foi realizada a partir de um mapeamento do perfil e da trajetória de egressos de um programa de pós-graduação em educação de uma universidade federal brasileira, que defenderam suas teses entre os anos de 2014 a 2016. Após a identificação de egressos que se encaixavam no perfil desejado para a pesquisa, a saber, recém-doutores que estavam atuando como docentes em cursos de licenciatura em universidades federais, eles foram convidados a escreverem suas narrativas (auto)biográficas sobre a inserção na docência no Ensino Superior. Dentre aproximadamente 60 docentes que aceitaram o convite, selecionamos seis dessas narrativas para compor o corpus para análise e discussão. Isto se justifica pelo fato das narrativas apresentarem de maneira explícita questões referentes à docência na educação a distância, foco deste artigo.

As seis narrativas selecionadas foram escritas por professores, aqui denominados de Carolina (Pedagogia), Celso (Química), Eduarda (Pedagogia), Luís (Física), Luísa (História) e Rodrigo (Matemática), que atuam em diferentes cursos de licenciatura em diversas universidades públicas, estaduais e federais. 
Estes seis professores selecionados do grupo de egressos que atendiam ao grupo investigado (recém-doutor e professor universitário em cursos de licenciatura) foram convidados a participarem da pesquisa sendo solicitados a escreverem suas narrativas (auto)biográficas sobre a docência universitária, as quais não obedeceram a um roteiro pré-determinado, apenas a seguinte orientação: "narre suas experiências em relação a docência universitária após a defesa da tese", o que possibilitou uma diversidade de temas e enfoques.

As pesquisas sobre a as narrativas (auto)biográficas, como de Passeggi e Cunha (2013), revelam que ao narrar, o autor passa a ser "compreendido como a pessoa que está na origem do ato de escrita e é por ele responsável. Nas narrativas (auto)biográficas, a pessoa que escreve é, ao mesmo tempo, o autor empírico do texto, o narrador e o protagonista do enredo da história" (p. 45).

Para analisar as narrativas produzidas pelos docentes, utilizamos a análise de conteúdo de Bardin (1977). A partir da leitura das narrativas elegemos a categoria "prática pedagógica" como elemento para análise. Na classificação das categorias de análise de conteúdo, o autor afirma que a "categorização é uma operação de classificação de elementos constitutivos de um conjunto, por diferenciação e, seguidamente, por reagrupamento segundo o gênero (analogia), com os critérios previamente definidos" (p.117).

\section{PRÁTICA DOCENTE NA EAD: ALGUMAS TENSÕES}

Pensar as práticas docentes em EaD é um processo sempre tensionado por escolhas e expectativas em relação às práticas pedagógicas utilizadas no processo de ensino. Selecionar e escolher estratégias pedagógicas para o trabalho no ambiente virtual e na construção da sala virtual implica, necessariamente, na prática do planejamento pedagógico feito pelos docentes. Que práticas são mais frequentes na EaD? Como os docentes escolhem e desenvolvem essas práticas? Com quais objetivos?

As narrativas escritas pelos professores sobre suas experiências na EaD trazem evidências das diferentes experiências vivenciadas pelos sujeitos nesta modalidade diante do processo de inserção na atuação pedagógica no Ensino Superior. O trecho a seguir evidencia um momento vivenciado por Eduarda na inserção na educação a distância: 
Minha experiência no campo educacional é enorme, mas sempre no presencial. Com EaD é pequena. Apenas fiz um material para um curso a Distância e agora estou trabalhando como professora de um curso em $\mathrm{EaD}$ (Trecho da narrativa. Professora Eduarda, 2017).

A professora Eduarda apresenta em seu relato a tensão entre a prática profissional no presencial e a distância, explicitando suas primeiras experiências como autora de material para um curso a distância. Faz a comparação com as suas experiências na modalidade presencial, sendo esta, bem mais consistente do que na EaD. Os estudos de Tardif (2002) sinalizam esta complexidade quando trata dos diferentes saberes.

Conforme mostram Moore e Kearsley (2008), as atividades e tarefas para a EaD precisam ser preparadas por especialistas no assunto a fim de que organizem os conteúdos específicos para a disciplina a ser trabalhada. Elaborar e desenvolver práticas inovadoras no ambiente virtual exige diferentes saberes docentes, como domínio de recursos tecnológicos, conhecimento do contexto educativo a distância, dentre outros.

$\mathrm{O}$ trecho a seguir reforça algumas percepções dos docentes frente ao trabalho com EaD:

Só após 15 anos trabalhando em curso superior e que me deparei com a aprendizagem do trabalho com a educação à distância e o ambiente virtual. Iniciei a aprendizagem e fui, no dia-a-dia, entrando no ambiente e me familiarizando com "a nova sala de aula virtual" que requer tempo e disponibilidade também. Minha primeira construção foi da disciplina de Didática e minha primeira dificuldade foi em relação a transposição de conteúdos para a sala virtual. Que práticas eu utilizaria no ambiente virtual? Mas, tive a oportunidade de ser orientada por outra docente que já tinha muito conhecimento em EaD (Trecho da narrativa. Professora Carolina, 2017).

Em relação ao trecho anterior, observa-se como o conhecimento tecnológico permaneceu desconhecido no campo profissional da docente. O relato mostra que a professora foi conhecendo, se "familiarizando" com a "sala virtual", o que reforça que a formação docente é um processo que envolve experiências anteriores e compartilhamento com os pares. A narrativa da professora evidências que o processo vivenciado na inserção na $\mathrm{EaD}$ e a busca por uma prática pedagógica neste contexto foram realizadas em um processo de aprendizagem advindo de dois vieses: a partir de uma busca pessoal e diária constante, além de um processo de socialização na colaboração com um sujeito mais experiente no campo de atuação na educação a 
distância. A questão do tempo e disponibilidade para atuar na modalidade a distância foi um aspecto importante apontado pela docente como um fator relevante na construção de saberes relacionado à prática pedagógica no ambiente virtual. A narrativa da professora Carolina evidencia também certa dificuldade no momento de planejar o ensino no ambiente virtual e traz a ideia de "transposição de conteúdos para a sala virtual", ou seja, como organizar os conteúdos nesta modalidade de ensino.

Sabe-se que as tecnologias da informação possuem diversos meios que podem proporcionar uma aprendizagem mais prazerosa. Conhecer as ferramentas disponíveis no ambiente virtual e dominar os recursos tecnológicos proporcionados pelo ambiente é fundamental para a construção de uma prática inovadora em $\mathrm{EaD}$.

A questão dos saberem advindos das experiências é evidenciada no trecho a seguir:

Durante o doutorado trabalhei como tutor em um curso de licenciatura em (...). Isso foi bom por várias razões. Uma delas foi aprender a utilizar a plataforma Moodle como mídia de comunicação com os alunos. Entretanto, dada a volumosa carga de atividades acadêmicas ou de estudo, limitei-me a aprender o básico. Como meu status era de professor eu podia manipular a página com bastante liberdade. (Trecho da narrativa - Professor Rodrigo, 2017).

$\mathrm{Na}$ narrativa do professor Rodrigo, nota-se que o docente possuía conhecimentos anteriores a sua atuação na $\mathrm{EaD}$, como tutor, conhecendo alguns elementos da ação didática neste contexto, como a plataforma Moodle. Entretanto, este limitou-se, conforme ele mesmo afirma, a "aprender o básico" para o exercício de trabalho no ambiente virtual. A questão do tempo aparece também no relato do professor como um empecilho para sua atuação e formação pedagógica.

A seguir, apresentamos o ponto de vista da professora Luísa, que também aponta a questão do tempo relacionada à formação docente:

Eu enfrento vários desafios hoje na docência como o uso de tecnologias, a diversidade de estudantes no contexto educacional, as relações pessoais com meus colegas de trabalho. Estou me sentindo angustiada, pois parece que não dá tempo da gente compreender tudo que precisamos para atuar em sala [...]. Preciso dominar novas tecnologias, novas línguas, ler novos livros, produzir artigos, orientar, ler, escrever, falar... [...]. Parece que o trabalho já exige meu domínio de tudo isso (tecnologias, línguas, referenciais atuais, produção etc.) o que não tive enquanto estudante. Agora, estou com esta sensação de não dar conta [...]. Quanto tempo será preciso para eu dominar novas tecnologias e usá-las? Como aprender tudo isso em tão pouco tempo? [...] minha formação não privilegiou o domínio dos recursos 
tecnológicos necessários a minha prática docente e quando ministrei uma disciplina de $\mathrm{EaD}$ isto ficou evidente: apenas repeti o que eu fazia no presencial tentando usar mais vídeos, fóruns e chats. Mas, é isto que se espera da EaD? Sei que não, mas como fazer e buscar uma formação que dê conta de me ajudar tão rápido? (Trecho da narrativa - Professora Luísa, 2017)

Ao expressar suas experiências de práticas em EaD, a professora Luísa apresenta várias atividades inerentes à prática docente universitária, considerando a exigência de conhecimento tecnológico que não foi aprendido em formação específica, e que no percurso de trabalho está sendo exigido. Que metodologias estão sendo utilizadas na EAD? Serão as mesmas adotadas em um curso presencial? Estas questões são apontadas no relato docente quando diz "apenas repeti o que eu fazia no presencial tentando usar mais vídeos, fóruns e chats". O professor demonstra com seu discurso que ensinar e aprender, hoje, são processos contínuos, que implicam modificar o conceito do que é uma sala de aula e as concepções do que é ser professor e ser estudante. Sua narrativa evidencia que a formação é esse processo contínuo e revela a importância no processo em $\mathrm{EaD}$ da abertura do professor para a aprendizagem de novas tecnologias, em busca de uma interação docente-discente sintonizada com os princípios educativos que orientam esta modalidade de ensino. Ao citar o uso de fóruns, chats e vídeos, a docente revela algumas práticas de uso na sala virtual utilizadas para mediar o processo interativo entre os sujeitos.

O professor Celso narra:

Em 2009 fui tutor presencial de uma disciplina do curso de licenciatura em Química. Neste período já havia percebido que como tutor havia necessidade de uma maior atenção no aprendizado dos estudantes do curso. O tutor perceber e identificar as dificuldades dos estudantes no aprendizado de determinados conceitos. Mas a interação com os estudantes é totalmente diferenciada. O curso só me passou o material da disciplina e eu tive que aprender sozinho. Senti muita dificuldade. Não entendia quais recursos existiam e aí fui descobrindo sozinho o que poderia usar. No doutorado tem o Moodle que poucos professores utilizam. Eu aprendi mais sobre o Moodle quanto fiz o meu estágio docente e quis explorar com os estudantes da graduação (Trecho da narrativa - Professor Celso, 2017).

O professor relata suas dificuldades na inserção no trabalho com educação a distância e com a plataforma Moodle. Sabe-se que nesse sistema aberto existem várias possibilidades de criação de atividades, sendo necessário dinamizar e otimizar as ações e sugerir atividades. Entretanto, o docente, em seu primeiro contato como tutor, afirma 
que foi "descobrindo sozinho o que poderia usar", evidenciando a escassez de uma formação docente voltada ao contexto virtual.

Já o professor Luís, ao narrar sua inserção na $\mathrm{EaD}$, aponta:

O meu processo de inserção em EaD foi conduzido por uma professora que já tinha conhecimento de tecnologias da informação e de uma equipe de professores que também possuíam conhecimentos tecnológicos. Descobrir a sala virtual foi como desvelar o mundo virtual para mim. Aprendi que existiam várias ferramentas que podem ser usadas e muitos objetos de aprendizagem para a construção da disciplina no ambiente virtual. Se eu não tivesse pessoas que conhecessem as tecnologias seria muito difícil querer ser tutor ou professor em modalidade em EaD. A ajuda deles foi crucial. Cheguei a utilizar wiki, chats, fóruns, jogos virtuais, glossário, cruzadinhas, criando atividades que possibilitassem a interdisciplinaridade (Trecho da narrativa - Professor Luís, 2017).

Ao narrar sua inserção em EaD, o professor Luís considera que a parceira com pessoas que dominavam os recursos tecnológicos foi crucial para que ele pudesse adentrar o mundo virtual. Observa-se que a ajuda de docentes com conhecimentos em tecnologia, designs e atividades de tutoria proporcionou segurança ao docente na inserção do ambiente de sala virtual. O professor revela a utilização de várias ferramentas importantes nesse meio, como chats, fóruns Wiki e glossário. Conforme apontam Mill e Fidalgo (2007, p. 20), a "utilização dessas tecnologias digitais de informação e comunicação possibilitou o redimensionamento do espaço temporal e maior interatividade entre alunos e docentes".

As narrativas dos docentes aqui apresentadas evidenciam práticas pedagógicas envolvendo o uso de recursos tecnológicos, ainda que de maneira tímida, e apontam para vários desafios enfrentados por eles na docência da educação a distância no contexto universitário.

Os resultados também indicam a necessidade de maior investimento na implementação de políticas de formação de professores para a docência universitária em relação ao conhecimento e domínio de recursos tecnológicos que possam ser mediadores de práticas pedagógicas inovadoras, tanto no contexto presencial quanto a distância. 


\section{ALGUNS APONTAMENTOS FINAIS}

Como discutimos durante o artigo, e a partir dos resultados da análise dos dados que foram apresentados, evidencia-se a necessidade de o professor da $\mathrm{EaD}$ ter uma formação para o uso das TIC, sobretudo, ao se tratar de recursos que permitem instaurar novas formas de interação entre professor e alunos.

No entanto, a inserção desse novo elemento mediador em sua prática pedagógica ainda causa estranhamento a muitos professores porque, de acordo com Lapa e Pretto (2010), não basta dominar o uso técnico do recurso, é preciso, também, dominar seu uso pedagógico. Para isso, torna-se fundamental, em primeiro momento, que o professor busque a mudança, mobilize seus conhecimentos e busque novos saberes. Não de forma individual, mas em contextos colaborativos e processos formativos vinculados a políticas públicas de formação que abracem estes desafios. Quando isso ocorrer, aí sim será possível o professor, para trabalhar na EaD, estar verdadeiramente amparado em um contexto colaborativo e por uma equipe de profissionais ligada ao uso de novos recursos tecnológicos. Além disso, desta forma ele poderá construir novas práticas pedagógicas próprias da educação a distância, rompendo com mitos e desafios em relação à EaD. Os resultados mostram que esse cenário, no qual o professor estará amparado por uma equipe colaborativa e recursos tecnológicos, infelizmente ainda se configura em poucos cursos e instituições.

As análises das narrativas dos recém-doutores, ingressantes na docência universitária, sinalizam que em muitos editais de concursos públicos para ingresso no magistério superior em universidades federais está previsto que o candidato, caso seja aprovado, poderá trabalhar na $\mathrm{EaD}$. $\mathrm{O}$ candidato se prepara para as provas do processo seletivo de acordo com a bibliografia sugerida e, muitas vezes, pode ser aprovado sem efetivamente ter experiência prática nessa modalidade de ensino, reforçando a fragmentação entre teoria e prática. Após o ingresso como docente, isso se torna um problema, pois este poderá atuar em um contexto educativo virtual, geralmente sem uma formação anterior ou que seja fornecida pelas instituições. Como trabalhar com aquilo que não se sabe? Haverá alguém para auxiliar? O professor fará cursos antes de assumir as aulas? Muitas vezes essas perguntas ficam sem respostas, e o professor acaba criando um caminho próprio, às vezes solitário, para atender, minimamente, às exigências do novo contexto educativo. 
Os resultados revelam que a questão da inovação em EaD implica, necessariamente, discutir sobre alguns componentes como o planejamento, a interação, e o ambiente de aprendizagem. Como sinaliza Moran (2003), inovar é necessário. Fazer com que a educação presencial se virtualize e a $\mathrm{EaD}$ se presencialize, rompendo com uma concepção dualista em direção a uma educação fundamentada em práticas pedagógicas transformadoras e emancipatórias, sejam elas, presenciais ou a distância.

\section{REFERÊNCIAS}

BARDIN, Laurence. Análise de Conteúdo. Lisboa: Edições 70, 1977.

BELLONI, Maria Luiza. Educação a distância. Autores Associados: Campinas, 1999.

BELLONI, Maria Luiza. Educação a distância e inovação tecnológica. Trabalho, Educação e Saúde, v.3, p. 187-198, 2005.

BEHRENS, Marilda Aparecida. Formação pedagógica on-line: caminhos para a qualificação da docência universitária. Em Aberto, Brasília, v. 23, n. 84, p. 47-66, nov. 2010 .

BRZEZINSKI, Iria. Profissão professor: identidade e profissionalização docente. Brasília: Plano Editora, 2002.

DELORY-MOMBERGER, Christine. Formação e socialização: os ateliês biográficos de projeto. Educação e Pesquisa, São Paulo, v.32, n.2, p. 359-371, maio/ago. 2006.

LAPA, Andrea; PRETTO, Nelson De Luca. Educação a distância e precarização do trabalho docente. Em aberto, Brasília, v. 23, n. 84, p. 79-97, 2010.

MELILLO, Kelly Maria de Campos Fornero Abreu de Lima. Em um dia, professor no ensino presencial... Em outro, professor na modalidade a distância? Ações que constituem a atividade de ser professor na EaD/UAB. 2011. 163 f. Dissertação (Mestrado Profissional em Educação Matemática). Instituto de Ciências Exatas e Biológicas, Universidade Federal de Ouro Preto, Ouro Preto, 2011.

MILL, Daniel. Docência virtual: uma visão crítica. Papirus, Campinas, 2012.

MILL, Daniel; FIDALGO, Fernando. Espaço, tempo e tecnologia no trabalho pedagógico: redimensionamento na Idade Mídia. Revista Brasileira de Estudos Pedagógicos, Brasília: v.88, n.220, p.421-444, set./dez. 2007.

MORAN, José Manuel. O ensino superior a distância no Brasil. Educação \& Linguagem, v. 12, n. 19, p.17-35, Jan.-Jun. 2009.

MORAN, José Manuel. Educação inovadora presencial e a distância. São Paulo: CA/USP, 2003. Disponível em: 
http://www.eca.usp.br/prof/moran/site/textos/tecnologias eduacacao/inov.pdf. Acesso em: 20 de janeiro. 2018.

MOORE, M. G; KEARSLEY, G. Educação a Distância: uma visão integrada. São Paulo: Cengage Learning, 2008. 398 p.

NÓVOA, António (org). Vidas de professores. Porto Editora, Porto, 1995.

PASSEGGI, Maria da Conceição; CUNHA, Luciana Medeiros da. Narrativas autobiográficas: a imersão no processo de autoria. 43-57. In: VICENTINI, Paula Perin; SOUZA, Elizeu Clementino de; PASSEGGI, Maria da Conceição. Pesquisa (auto)biográfica. Questões de ensino e formação. Curitiba, PR: CRV, 2013.

SILVA, Marco. Educação a distância (EaD) e educação online (EOL) nas reuniões do GT 16 da Anped, 2000-2010. Revista Teias. v. 13, n. 30, 95-118, set./dez. 2012.

SÁ Helena; SILVA, Marco. Mediação docente e desenho didático: uma articulação complexa na educação online Rev. Diálogo Educ., Curitiba, v. 13, n. 38, p. 139-159, jan./abr. 2013.

SILVA, Marco et al. Educação e comunicação interativas: contribuições para o desenho didático e para a mediação docente na educação on-line. In: SILVA, Marco (Org.). Formação de professores para docência on-line. São Paulo: Loyola, 2012. p. 89.

SOUZA, Elizeu Clementino de; PASSEGGI, Maria da Conceição; VICENTINI, Paula Perin. (Org). Pesquisa (auto)biográfica: trajetórias de formação e profissionalização. $1^{\mathrm{a}}$ ed. Curitiba, PR: CRV, 2013.

SOUZA, Elizeu Clementino de. O conhecimento de si: estágio e narrativas de formação de professores. Rio de Janeiro: DP\&A; Salvador. BA; UNEB, 2006.

TARDIF, Maurice. Saberes profissionais dos professores e conhecimentos universitários: elementos para uma epistemologia da prática profissional dos professores e suas consequências em relação à formação para o magistério. Revista Brasileira de Educação, Belo Horizonte, n. 13, p. 5-24, 2000.

TARDIF, Maurice. Saberes docentes e formação profissional. Petrópolis: Vozes, 2002.

TORRES, Alda Roberta; ALMEIDA, Maria Isabel de. Formação de professores e suas relações com a pedagogia para a educação superior. Form. Doc., Belo Horizonte, v. 05, n. 09, p. 11-22, jul./dez. 2013.

VIANNEY, J. A ameaça de um modelo único para a EaD no Brasil. Colabor@ Revista Digital da CVA-RICEU, v. 5, n.17, jul. 2008. Disponível em:http://www.ricesu.com.br/colabora/n17/index1.htm. Acesso em 23 de janeiro de 2018. 
